\title{
Farnsworth-Munsell 100 Hue Test
}

National Cancer Institute

\section{Source}

National Cancer Institute. Farnsworth-Munsell 100 Hue Test. NCI Thesaurus. Code C130172.

A diagrammatic method to test color blindness or deficiencies, which uses 100 colors from the Munsell color system arranged in rows of four color families, containing 25 hues for each color. The subject must put the hues in order based on the anchor colors at the ends of each row. 